REVISTA DE DERECHO UNED, NÚM. 18, 2016

\title{
COMUNIDADES QUE EJERCEN ACTIVIDAD EMPRESARIAL
}

\section{ENTITIES WHICH ENGAGE IN BUSINESS ACTIVITIES}

\author{
Carmen Muñoz Delgado \\ Profesora Asociada UNED \\ Doctoranda en Derecho por la UNED
}

Resumen: La comunidad de bienes como forma de ejercer una actividad empresarial es una realidad en el tráfico económico-mercantil. Son entes sin personalidad jurídica, reconocidos por determinados sectores del ordenamiento jurídico a sus propios fines, que carecen de un régimen jurídico propio. Determinar cuáles son sus características esenciales y cuál es su relación con la comunidad de bienes regulada en el Código civil o con la sociedad, permite centrar el debate sobre su calificación y sobre el régimen aplicable. Aceptadas por la doctrina y la jurisprudencia, su reconocimiento y régimen jurídico son objeto de propuesta de regulación por el legislador.

Abstract: Joint ownership, as a way of performing a business transaction, is a reality in financial and commercial dealings. It involves entities without a legal identity which, although they are recognized by certain sectors of the legal system for their own purposes, are without a specific legal status. Defining their essential characteristics and their relationship with joint ownership as regulated by the Civil Code or with the society, makes it possible to focus discussion on their status and the rules which are applicable to them. Although they are accepted by doctrine and case law, their recognition and legal status are the subject of a proposal for regulation on the part of the legislator.

Palabras clave: Ejercicio de la actividad empresarial. Comunidad de bienes. Sociedad. Sociedad irregular. 
Keywords: Performance of a business transaction. Joint ownership. Association. Society. Irregular association.

Recepción original: 28/12/2015

Aceptación original: 6/04/2016

Sumario: I. Introducción. II. Origen y caracteres. III. Naturaleza jurídica: comunidad o sociedad. 3.1 Comunidad de bienes. 3.2 Sociedad. A) Origen. B) Fin u objeto. C) Voluntad de los interesados: constituir una sociedad o crear una comunidad de bienes. D) Atribución legal de personalidad jurídica. La sociedad interna. E) Integración de los criterios. IV. Calificación de la relación jurídica subyacente. V. Régimen jurídico aplicable. VI. Propuesta legislativa de regulación. VII. Conclusiones. VIII. Bibliografía.

\section{INTRODUCCIÓN}

La comunidad de bienes, como forma de ejercer una actividad empresarial, viene siendo objeto de estudio por la doctrina desde hace tiempo. Sin embargo, es un tema que vuelve a adquirir plena vigencia en los últimos años a consecuencia de la propuesta de un nuevo Código Mercantil.

Esta vigencia se refleja en nuestro tráfico económico-mercantil. Según el Directorio Central de Empresas (DIRCE), la comunidad de bienes en nuestro país ocupa el tercer lugar como forma de explotar una empresa, tras el empresario individual y la sociedad de responsabilidad limitada ${ }^{1}$.

La comunidad de bienes se muestra como un instrumento que permite que varios sujetos se asocien para explotar una actividad empresarial en común sin adoptar una forma societaria tipificada. Así, por ejemplo, dos o más personas se unen para desarrollar un proyecto con el que obtener una ganancia; los cónyuges explotan conjuntamente un negocio, solos o con sus hijos u otros familiares; los herederos suceden en la empresa al fundador fallecido. El interés de todos es idéntico: la obtención de un lucro con el desarrollo de la actividad que le sirva de fuente de ingresos, así como asegurar la continuidad de la empresa mediante su gestión y control.

${ }^{1}$ El Retrato de las PYME 2016, Directorio Central de Empresas (DIRCE), elaborado por la Dirección General de Industria y de la Pequeña y Mediana Empresa, enero 2016 (http://www.ipyme.org/Publicaciones/Retrato_PYME_DIRCE_1_enero_2015.pdf) 
Estas comunidades son conocidas por actuar bajo una denominación seguida de las siglas C. B. y se les exige una serie de requisitos para poder ejercer su actividad frente a terceros (entre otros, solicitud de un NIF, alta en el censo de empresarios, alta en el Impuesto sobre Actividades Económicas, registros contables, comunicación de centros de trabajo, licencias de actividad, obligaciones en relación con la Seguridad Social, etc. $)^{2}$.

La calificación de esta relación se ha llevado a cabo por la doctrina y la jurisprudencia atendiendo a las similitudes y diferencias con otras formas de ejercicio de la actividad empresarial. Se parte de la comparación con la comunidad de bienes regulada en el Código civil o con la sociedad -aunque en esta última exista personificación-, para determinar cuál es su verdadera naturaleza jurídica y, en consecuencia, poder fijar el régimen aplicable a esta figura.

En nuestro Derecho comparado, también se han suscitado realidades similares aunque no idénticas a la que plantea en nuestro país la comunidad que ejerce una actividad empresarial. Son situaciones societarias en las que la voluntad de los que ejercen la actividad no se manifiesta de forma clara. Es el caso, por ejemplo, de la comunione d'azienda y la societá di fatto en Italia o la société créée de fait en Francia.

Se está, por tanto, ante una figura asociativa conocida pero no tipificada en el ordenamiento jurídico ${ }^{3}$. Es ahora con el Anteproyecto de Código Mercantil cuando se viene a dar un reconocimiento legal a esta figura equiparándola a las sociedades mercantiles, lo que, sin duda, tendrá como consecuencia una mayor seguridad jurídica en el tráfico económico, en beneficio de los terceros.

\section{ORIGEN Y CARACTERES}

El origen de estas comunidades es diverso: se puede derivar de la propia ley o nacer como consecuencia de un hecho, acto o negocio jurídico. Por ejemplo, que los herederos del empresario fallecido continúen su empresa o que los cónyuges mantengan el negocio que regentan tras la ruptura del vínculo matrimonial cuando rige el régimen legal de sociedad de gananciales son supuestos de comunidades

2 "Comunidad de bienes: creación y puesta en marcha», Colección PYME: ciclo vital de la empresa, Ministerio de Industria, Energía y Turismo, junio 2015 (www.ipyme.org)

${ }^{3}$ Excluidas expresamente del ámbito de aplicación de la Ley Orgánica 1/2002, de 22 de marzo, reguladora del Derecho de Asociación (art. 1.4). 
incidentales en las que se ejerce una actividad empresarial ${ }^{4}$. No obstante, lo habitual es que la comunidad que ejerce una actividad empresarial sea una comunidad voluntaria que se constituye a través de un negocio celebrado por dos o más sujetos al que aportan unos bienes propios o adquiridos en común para ejercer una actividad empresarial.

Elemento volitivo que podría decirse que también está presente en las comunidades incidentales, no en su origen pero sí como configuración de una comunidad ya existente. Así, la comunidad formada por los herederos o los excónyuges requiere no solo del acuerdo de continuar la explotación de forma conjunta -aunque no se manifieste explícitamente sino que se derive de los propios actos o de hechos concluyentes- sino de la forma en que se va a llevar a cabo.

En definitiva, la mayoría de comunidades que actúan en el tráfico son comunidades basadas en la voluntad de sus partícipes, manifestada en un pacto o contrato ${ }^{5}$, en el que los partícipes fijan su denominación, objeto, domicilio, duración, aportaciones, reparto de beneficios y cargas, así como aquellos pactos y normas que han de regir su funcionamiento, administración, sucesión y disolución (a modo de estatutos sociales y con apoyo legal en el art. 392.2 Cc). Se está ante un supuesto de lo que la doctrina denomina «comunidad convencional constitutiva», contrato necesariamente atípico ${ }^{6}$.

Se busca, a través de este instrumento, por tanto, conseguir una apariencia unificada en el tráfico, una subjetivación, aunque no puede olvidarse que la comunidad carece de personalidad jurídica y autonomía patrimonial propia (art. $35 \mathrm{Cc})^{7}$. Falta de personalidad jurídica que obliga a los partícipes a actuar frente a terceros en nombre

${ }^{4}$ GARRIGUES, en su dictamen 117, al tratar de un caso en que se continúan por el socio los negocios de la sociedad regular colectiva, extinguida la sociedad primitiva por la muerte de otro socio, sin constituir ninguna otra de índole regular ni irregular, concluye que se forma una comunión incidental de bienes, ya que, «la explotación de una empresa mercantil bajo la forma de comunidad es frecuente en los casos de la comunidad incidental producida por el hecho de la sucesión de varias personas en un mismo negocio» (Dictámenes de Derecho Mercantil, II, Madrid, 1976, p. 365).

${ }^{5}$ El contrato puede ser verbal o escrito, privado o público. La escritura pública es obligatoria si se aporta un bien inmueble. Modelo de contrato de una comunidad de bienes, en "La comunidad de bienes», en Guía de Derecho Civil, Teoría y práctica, tomo IV, ed. Aranzadi, S. A., enero 2013 (Aranzadi digital, BIB 2013/16097).

${ }^{6}$ ALBIEZ DOHRMANN, K. J.: "Contratos sobre comunidades convencionales. Cláusulas usuales», en Comunidad de bienes, coord. por M. ${ }^{\mathrm{a}}$ J. REYES LÓPEZ, Tirant lo Blanch, Valencia, 2014, pp. 1032-1033.

${ }^{7}$ Salvo excepciones, como la capacidad para ser demandadas (art. 6.2. LEC) o para ser arrendatarias en los arrendamientos rústicos (art. 9.2 Ley 49/2003, de 26 de noviembre, de Arrendamientos rústicos). 
propio, asumiendo la responsabilidad derivada de las distintas operaciones aunque su actuación esté sujeta a lo dispuesto en sus normas reguladoras sobre gestión y representación (nombramiento de un único apoderado; actuación mancomunada o conjunta; uno de ellos con poder de los demás...) o por lo establecido en disposiciones especiales ${ }^{8}$.

La falta de personalidad jurídica, precisamente, es la que impide que estas comunidades, aunque ejerzan una actividad mercantil, tengan la consideración de empresario y, por tanto, queden sometidas a su estatuto jurídico. Esta afirmación, sin embargo, debe ser matizada.

En cuanto a la llevanza de contabilidad existe la obligación de asignar sus activos, pasivos, ingresos y gastos a los partícipes en la proporción que les corresponda ${ }^{9}$, lo que requiere de su identificación y registro. De ahí que, en la práctica, lleven contabilidad propia e independiente para facilitar dicha asignación.

Son sujetos que no tienen acceso al Registro Mercantil ${ }^{10}$, aunque se admite que los comuneros accedan como empresarios individuales, haciéndose constar, en su caso, que los mismos son titulares de una determinada cuota en una comunidad determinada. La comunidad no es objeto de inscripción como empresario directamente sino a través de sus miembros como empresarios individuales ${ }^{11}$.

De ahí que no puedan legalizar sus libros ${ }^{12}$. Sin embargo, si una disposición especial obliga a estas comunidades a formular su contabilidad conforme a las normas del Código de comercio ${ }^{13}$, sus libros deben someterse a legalización aunque la comunidad no esté inscrita como empresario.

${ }^{8}$ Un ejemplo se encuentra en las cláusulas en cuenta bancaria a la vista: «En caso de que el titular sea una comunidad de bienes, una Sociedad Civil, o cualquier otro tipo de entidad sin personalidad jurídica, sus componentes se apoderan recíprocamente para que cualquiera de ellos y con su sola firma pueda realizar cualquiera de las operaciones derivadas del presente contrato, respondiendo todos ellos con carácter personal y solidario de las obligaciones derivadas del mismo».

${ }_{9}$ Norma de registro y valoración 20 del Plan General de Contabilidad (Real Decreto $1514 / 2007$, de 16 de noviembre) y 19 del Plan General de Contabilidad de Pequeñas y Medianas Empresas y los criterios contables específicos para microempresas (Real Decreto 1515/2007, de 16 de noviembre).

${ }^{10}$ Según el principio registral de tipicidad solo pueden ser objeto de inscripción los empresarios y demás sujetos establecidos por la ley.

${ }^{11}$ CANO ZAMORANO, L., "La comunidad de bienes y su relación con el Registro Mercantil», en M. J. REYES LÓPEZ (Coord.), Comunidad de bienes, Tirant lo Blanch, Valencia, 2014, p. 722.

${ }^{12}$ RDGRN 16 de febrero de 2000.

${ }_{13}$ Artículo 68, apartado 2, Real Decreto 439/2007, de 30 de marzo, por el que se aprueba el Reglamento del Impuesto sobre la Renta de las Personas Físicas. 
Por otra parte, su especial configuración hace que, para determinados sectores del ordenamiento jurídico y a sus propios fines, las comunidades que ejercen una actividad empresarial sean reconocidas como sujetos con cierta capacidad de obrar e incluso sean consideradas empresarios, como sucede en el ámbito tributario y laboral.

A efectos de tributación, la legislación equipara estas comunidades a sociedades, siempre que se constituyan por actos inter vivos para realizar actividades empresariales y cuando se constituyan $\mathrm{u}$ originen por actos mortis causa si la explotación del negocio del causante continúa en régimen de indivisión por un plazo superior a tres años ${ }^{14}$. En el ejercicio de la actividad se les considera sujetos pasivos ${ }^{15}$, por ser un medio a través del cual se manifiesta una capacidad económica, objeto de gravamen ${ }^{16}$. Por ello se les atribuye un NIF y están obligadas a actuar bajo un epígrafe del Impuesto sobre Actividad Económicas.

De igual forma, en el ámbito laboral la comunidad se considera empresario con capacidad para contratar trabajadores ${ }^{17}$, con las obligaciones propias de la empresa en relación con la Seguridad Social.

En definitiva, podría concluirse que la comunidad es un instrumento técnico-jurídico por el que, mediante la aportación de bienes o derechos, sus miembros explotan una empresa con el fin de obtener un lucro, sujetos a una organización y bajo una serie de atributos que

${ }^{14}$ Art. 22, apartados 4 y 5, RD-Legislativo 1/1993, de 24 de septiembre, por el que se aprueba el T. R. de la Ley del Impuesto sobre Transmisiones Patrimoniales y Actos Jurídicos Documentados. Con apoyo en esta misma norma, se admite la equiparación de estas comunidades a las sociedades para acogerse a la neutralidad fiscal de la fusión de sociedades.

${ }^{15}$ En el ordenamiento tributario las comunidades de bienes se consideran obligados tributarios (art. 35.4 LGT), con capacidad de obrar en el tráfico jurídico y, por tanto, sujetos pasivos sometidos a tributación en relación con la imposición indirecta. Sin embargo, los rendimientos obtenidos en sus actividades serán atribuidos a los comuneros como rendimientos de actividades empresariales y, por tanto están sujetos al Impuesto sobre la renta de las personas físicas y no al Impuesto sobre sociedades (tras la reforma de este impuesto es de interés la Instrucción de la Agencia Tributaria en relación con la constitución de comunidades de bienes a partir de 2015, donde se matiza que la forma jurídica de comunidad de bienes o sociedad civil no va «a depender de la voluntad de los contribuyentes, sino de la correcta calificación de la naturaleza jurídica de la entidad»).

${ }^{16}$ SOLER ROCH, M. ${ }^{\text {a }}$ T., Prólogo a la obra de BAYONA GIMÉNEZ, J. J., Tributación de la comunidad de bienes, Marcial Pons, Madrid, 1997, p. 9, dice que: «la comunidad de bienes, más allá de la mera situación jurídica de copropiedad que ya configurara el viejo Derecho romano, se ha convertido en la actualidad en un importante mecanismo asociativo que actúa como centro de imputación autónomo de obtención, conservación y transformación de riqueza».

${ }^{17}$ Art. 1.2. Real Decreto Legislativo 2/2015, de 23 de octubre, por el que se aprueba el texto refundido de la Ley del Estatuto de los Trabajadores. 
les permite su participación unificada en el tráfico jurídico-económico con una aparente capacidad jurídica.

\section{NATURALEZA JURÍDICA: COMUNIDAD O SOCIEDAD}

Se evidencia de la configuración de estas comunidades la existencia de rasgos comunes a otros instrumentos técnicos o formas de ejercer la actividad ${ }^{18}$. Por ello, determinar cuál es la verdadera naturaleza de esta relación jurídica se ha convertido en una cuestión de importancia para la doctrina, los tribunales y los intérpretes del Derecho (abogados, notarios, registradores..).

\subsection{Comunidad de bienes}

La comunidad de bienes se regula en el Código civil como la propiedad de una cosa o de un mismo derecho cuando pertenece pro indiviso a varias personas (art. 392).

La definición legal de comunidad no hace referencia a su origen ni a la voluntad de los partícipes, sino que describe un supuesto de hecho -la pertenencia de una cosa o la pertenencia de un derecho a varias personas pro indiviso-, cuya consecuencia jurídica es que hay comunidad $^{19}$.

18 «Existencia de cuatro instrumentos técnicos distintos de subjetivación: En primer lugar, la societas, que se mueve en un plano jurídico-obligacional puro, aunque puede ir acompañada en un plano jurídico-patrimonial de una situación de cotitularidad. En segundo lugar, la "comunidad romana" o por cuotas, que cumple una función de goce pasivo de un patrimonio en situación de cotitularidad, pudiendo cualquier comunero instar la disolución (art. $400 \mathrm{Cc}$ ); limitándose a regular las actividades de conservación y uso independiente de las cosas, su carácter es transitorio y no permite la afectación del patrimonio a un fin común más o menos permanente. Frente a ella, la comunidad germánica o de mano común caracterizada por la idea de que la parte se refiere al conjunto patrimonial, cuya titularidad viene atribuida "conjuntis manibus" a la colectividad de personas como tal, lo que supone una separación del patrimonio común respecto del particular de los miembros, quedando aquél afectado al fin común merced no sólo a la separación de deudas sino al sistema de prelación de los acreedores de la comunidad. El último corresponde a la personalidad jurídica, en la que la subjetivación colectiva se apoya en una organización, en cierto modo, abstracta y objetivada, creándose un sujeto de derecho dotado de patrimonio independiente y perfectamente acotado y responsable». Síntesis efectuada por FERNÁNDEZ DE LA GÁNDARA, L., siguiendo a GIRON TENA, en Derecho de sociedades, vol. I, Tirant lo blanch, Valencia, 2010, pp. 69-70. También CÁMARA, M. de la, Estudios de Derecho Mercantil, I, Editoriales de Derecho Reunidas, Madrid, 1977, pp. 68 ss.

${ }^{19}$ MIQUEL GONZÁLEZ, J. M., "Artículo 392», en Comentarios al Código Civil, tomo V, vol. 2. ${ }^{\circ}$, dir. por M. ALBALADEJO, Edersa, 1985 (vlex.com/vid/artículo-392-229937). 
Ello permite delimitar los requisitos exigidos para que exista comunidad: a) una sola relación jurídica entre la pluralidad de titulares y el objeto, siendo el vínculo indivisible materialmente; b) un único objeto (cosa, masa patrimonial, universalidad de cosas) que ha de ser indivisible materialmente, ya que si el objeto puede dividirse existiría una comunidad pro diviso, que es supuesto de cotitularidad más que de estricta comunidad; c) una pluralidad de sujetos de modo simultáneo y no sucesivo; y d) un conjunto de titularidades de idéntico contenido cualitativo -de idéntica naturaleza, mismas facultades y potestades-, aunque no necesariamente en cuanto su proporción cuantitativa ${ }^{20}$.

Los comuneros tienen asignadas unas cuotas que determinan la proporción en que participan en el uso y en los beneficios y cargas de la cosa común (arts. 393 a 395), así como en la adopción de acuerdos para su mejor administración y disfrute (art. 398). Estas cuotas, aunque no son parte material de la cosa -indivisa físicamente-, representan una parte abstracta de ella, con un valor determinado que las hacen objeto de negocios jurídicos con carácter separado e individual (art. 399).

El Código civil se adscribe así al sistema romano de comunidades por cuotas $^{21}$, delimitando el supuesto de hecho a la propiedad de un bien y, por tanto, centrándose, al recaer sobre un derecho real, en la denominada copropiedad, condominio, proindiviso.

Frente a esta concepción estática de comunidad del Código civil están las comunidades a las que nos venimos refiriendo, que son comunidades dinámicas, denominadas por algunos autores «comunidades funcionales», que se caracterizan por su origen volitivo, su estabilidad, la existencia de un fin común entre los partícipes y su organización ${ }^{22}$.

${ }^{20}$ BELTRÁN DE HEREDIA Y CASTAÑO, J., La comunidad de bienes en Derecho español, Ed. Revista de Derecho Privado, Madrid, 1954, pp. 27-30.

${ }^{21}$ Criterios de diferenciación entre comunidades germánicas y romanas, ALBALADEJO, M., Curso de Derecho Civil. III. Derecho de bienes, Bosch, 2002, pp. 368 ss.; BAYONA GIMÉNEZ, J. J., en Tributación de la comunidad de bienes, Marcial Pons, Madrid, 1997, p. 15 ss. y una síntesis en p. 19.

${ }^{22}$ v. sobre comunidad funcional, PAU PEDRÓN, A., "Comunidad funcional», en Libro Homenaje a Manuel Peña Bernaldo de Quirós y Antonio Ipiéns Llorca, Colegio de Registradores de la Propiedad y Mercantiles de España, Madrid, 1996, p. 281 ss., que plantea si estas comunidades están sujetas a la acción de división y al derecho de retracto o si son comunidades atípicas regidas por principios distintos de los que inspiran la regulación legal; y PÉREZ PÉREZ, E., Propiedad, Comunidad y Finca Registral, Colegio de Registradores de la Propiedad y Mercantiles de España, Madrid, 1995, pp. 189 ss., donde analiza sus elementos partiendo de la RDGRN de 25 de mayo de 1983 (en el supuesto de explotación de inmuebles). 
Ambas realidades, aunque comparten denominación, se diferencian en su esencia. La comunidad, en su sentido dinámico-funcional, supone la unión de varios sujetos para ejercer una actividad común y obtener un beneficio repartible entre todos y no solo en la titularidad y disfrute en común de un bien o conjunto de bienes. Los sujetos concurren no en torno a ese bien o conjunto de bienes sino con una finalidad, llevar a cabo conjuntamente una actividad empresarial en el tráfico económico. La tenencia de bienes en común es accesoria al fin, se aportan para poder llevar a cabo la actividad ${ }^{23}$.

No es, por tanto, la comunidad que ejerce una actividad empresarial una forma de comunidad encuadrable dentro del régimen jurídico de las comunidades de bienes strictu sensu ${ }^{24}$.

Transcienden de la mera copropiedad, tienen cierta subjetivación (actuación unificada en el tráfico), aunque no tengan autonomía propia, al carecer de personalidad jurídica.

\subsection{Sociedad}

Es suficiente con comparar la regulación por el Código civil de la sociedad y la comunidad strictu sensu para demostrar su diferente naturaleza. Así, es de destacar que en la comunidad los bienes y derechos que se ponen en común pertenecen a los condóminos por cuotas mientras que en la sociedad lo aportado pasa a formar parte del patrimonio social, en virtud de un especial negocio traslativo. La cuota implica un derecho de naturaleza real y la participación del socio en el patrimonio de la sociedad representa un derecho sobre los beneficios y pérdidas y, para el caso de liquidación, una cuota en el patrimonio social.

La distinción comunidad y sociedad ha sido tratada por la doctrina ampliamente ${ }^{25}$, basándose en criterios diversos y con distinto al-

${ }^{23}$ SAP Salamanca, núm. 85/2000, de 8 de febrero.

${ }^{24}$ En este sentido, GIRON TENA destacó que «el sentido dinámico de la explotación comercial no es casable con el concepto de copropiedad romana de nuestro Código Civil, que está pensado para una simple actividad conservativa y no para una explotación esencialmente dinámica»(GIRON TENA, J.: Derecho de Sociedades, tomo I, Madrid 1976, p. 83 ss).

${ }^{25}$ Entre otros, ALBALADEJO, M.: «La distinción entre comunidad y sociedad», en Actualidad Civil, núm. 33, vol. 1995-3, pp. 669 a 682; BELTRÁN DE HEREDIA Y CASTAÑO, J.: La comunidad de bienes en Derecho Español, op. cit., pp. 35 a 71; MIQUEL GONZÁLEZ, J. M.: «Comentario al art. 392 Cc», en Código Civil y Compilaciones Forales, dir. por M. ALBALADEJO, Madrid, 1985 (vlex.com/vid/articulo-392-229937); TENA PIAZUELO, I.: La caracterización de la sociedad civil y su diferencia con la comunidad de bienes, Tirant lo Blanch, Valencia, 1997. 
cance, pero que en su conjunto han permitido llegar a la conclusión de que comunidad y sociedad son dos instituciones jurídicas, distintas, con importantes diferencias estructurales.

Esta distinción parte de la situación pura de comunidad, pero, como se ha visto, la comunidad que ejerce una actividad empresarial se aleja de la concepción estática prevista en el Código civil para las comunidades. Se trata ahora de determinar si la aplicación de estos criterios permitiría afirmar igualmente que una comunidad que ejerce una actividad empresarial y una sociedad son dos figuras jurídicas relevantemente distintas.

\section{A) Origen}

Este criterio se basa en que la sociedad tiene necesariamente un origen voluntario manifestado a través de un contrato (art. $1665 \mathrm{Cc}$ y $116 \mathrm{C}$ de c), mientras que la comunidad no tiene una regulación específica en cuanto a su nacimiento, se origina normalmente con total independencia de la voluntad de las partes, de forma incidental. La comunidad puede tener su origen en la ley, en un negocio jurídico o en un hecho de naturaleza independiente de todo acuerdo voluntario.

Un sector doctrinal, matizando este criterio, afirma que la distinción consiste en que la comunidad no puede tener su origen en un contrato, ya que no surge por el mero consentimiento sino por los modos de adquirir el dominio. Si varios quieren constituir una comunidad de bienes obligándose a ello y por cierto tiempo, no surge la comunidad por el contrato, sino por las aportaciones efectivamente realizadas ${ }^{26}$. Otro sector, por el contrario, no otorga valor a este criterio por varias razones, entre ellas, los diversos orígenes de la comunidad y la naturaleza jurídica de la sociedad que no se trata de un simple contrato ${ }^{27}$.

En las comunidades que ejercen una actividad empresarial, como hemos visto, la voluntad de las partes juega un papel fundamental (comunidad convencional) $^{28}$, no solo en el momento de su nacimiento sino en la determinación de las reglas de funcionamiento y de estructura organizativa (a modo de pactos sociales).

${ }^{26}$ MIQUEL GONZÁLEZ, J. M., «Comentario al art. 392», op. cit.

${ }^{27}$ BELTRAN DE HEREDIA Y CASTAÑO, J.: La comunidad de bienes en el Derecho español, op. cit., p. 42.

${ }^{28}$ Sobre las distintas posturas doctrinales y la naturaleza de la comunidad convencional constitutiva, ALBIEZ DOHRMANN, K. J.: «Contratos sobre comunidades convencionales. Cláusulas usuales», op. cit., pp. 1034 ss. 
El origen no sería, por tanto, un criterio lo suficientemente diferenciador.

\section{B) Fin u objeto}

La corriente doctrinal tradicional defiende que la comunidad comprende un conjunto de intereses distintos que se armonizan pero no se funden en un interés único, siendo el interés común la suma de los intereses individuales ${ }^{29}$. En la sociedad, por el contrario, existe una comunidad de fin, existe un fin común, distinto de los intereses de cada uno de los socios ${ }^{30}$ : la obtención de una ganancia (art. $1665 \mathrm{Cc}$ ), consecuencia de su relación con terceros.

Otros autores llegan a la misma conclusión, considerando, en lugar del fin, la actividad como elemento diferenciador. La sociedad es el vehículo para el ejercicio de una actividad con la que obtener el lucro o la ganancia, mientras que la comunidad no ejerce actividad sino que se limita a la mera conservación, disfrute o aprovechamiento del patrimonio (explotación estática o por cesión a cambio de precio $)^{31}$.

La diferencia pues se encuentra en la existencia o no de un fin común y en la organización de los medios personales y materiales para su consecución. En este sentido, la STS, 1. ${ }^{\text {a }}, 17$ de julio de $2012^{32}$, es clara: la sociedad, como situación dinámica, ordena su explotación con arreglo a una organización económica de sus medios (empresa) y con la finalidad preferente de lograr unas ganancias para partirlas entre sus partícipes, a diferencia de la comunidad que ordena su explotación, de forma estática, con arreglo a la mera utilización y aprovechamiento consorcial de los bienes, conforme a su función productiva y a la finalidad de conservación o mantenimiento de los mismos.

${ }^{29}$ Para un estudio de la comunidad de intereses, v. PÉREZ PÉREZ, E., Propiedad, Comunidad y Finca Registral, op. cit., pp. 189 ss.

${ }^{30}$ BELTRAN DE HEREDIA Y CASTAÑO, resalta que «lo decisivo aquí, no es tener, ni poner en común, sino hacer algo en común, persiguiendo un mismo fin», en $L a$ comunidad de bienes en Derecho Español, op. cit., p. 32.

${ }^{31}$ FERNÁNDEZ DE LA GÁNDARA, L., manifiesta que estas comunidades no son una figura autónoma dentro de los fenómenos asociativos, sino una «particular forma de organizar la titularidad sobre el patrimonio», ya que, en la sociedad, los bienes están en función de la actividad, orientada a la promoción del fin, mientras que en la comunidad la actividad está en función de los bienes y el ejercicio sirve a los fines singulares y privados de cada uno de los intervinientes, que «tienen derecho a la adopción de las medidas legales sobre mantenimiento y administración del objeto común», en Derecho de Sociedades, vol. I, op. cit., p. 50-51.

32 Sentencia núm. 471/2012. 
Este criterio de diferenciación, sin embargo, es superado por la situación de la que se parte. Las comunidades que ejercen una actividad empresarial se constituyen con el fin de obtener ganancias con la actividad que desarrollan sus partícipes y poder distribuir o repartir los beneficios entre ellos. Existe ánimo de lucro en el ejercicio de esa actividad.

\section{C) Voluntad de los interesados: constituir una sociedad o crear una comunidad de bienes}

Se ha defendido que la diferencia entre comunidad y sociedad no está en que esta última se organice para obtener ganancias y aquélla no, «sino en haber querido, para conseguir la ganancia, una comunidad o una sociedad» ${ }^{33}$.

Se fija, en definitiva, como criterio decisivo para diferenciar a la sociedad de cualquier otro modelo de comunidad patrimonial, la intención de formar sociedad ${ }^{34}$. La decisión de los socios de someterse a los rasgos esenciales que determinan el concepto legal de sociedad y a sus principios configuradores (igualdad de trato $^{35} \mathrm{y}$ deber de fidelidad ${ }^{36}$ ), supone una actuación basada en la confianza recíproca y en la colaboración entre los socios, lo que se traduce, en términos positivos, en la promoción del fin común y, en términos negativos, en la prohibición de obtener ventajas particulares a costa del sacrificio de la sociedad o la subordinación a los intereses particulares de los inte-

${ }^{33}$ ALBALADEJO, Derecho Civil, III Derecho de Bienes, op. cit., p. 373. En su anterior trabajo, «la distinción entre comunidad y sociedad», tras un exhaustivo estudio de los criterios de distinción y del análisis de la jurisprudencia y la doctrina, ya concluía que «la distinción entre sociedad y comunidad se basa no en que objetivamente, y con independencia de la voluntad de las partes haya en un caso sólo uso y disfrute y en otro explotación, sino en que subjetivamente en un caso haya habido voluntad de sociedad y en el otro no» (op. cit., pp. 676-677).

${ }^{34}$ La affectio societatis es calificada por la jurisprudencia de múltiples formas «intención social», "voluntad de unión de una pluralidad de sujetos para correr en común ciertos riesgos», voluntad de crear la sociedad, es decir, el consentimiento de los contratantes»... v. para un listado completo, GRIMALDOS GARCÍA, M. I., ¿Sociedad interna o comunidad de bienes?: criterios de distinción en nuestra jurisprudencia. A propósito de la STS, 1. a, de 17 de julio de 2012, en Diario la Ley, núm. 8056, 5 de abril 2013, Ref. D-127 (La Ley 1739/2013), en especial nota 12.

${ }^{35}$ Introducido explícitamente en la regulación de las sociedades anónimas por la Ley 3/2009, de modificaciones estructurales de las sociedades mercantiles (actual art. 97 LSC), aunque la generalidad de la doctrina ha considerado dicho principio configurador de cualquier tipo de sociedades, al derivarse del propio contrato de sociedad. C. de c.

${ }^{36}$ Reflejo del principio de buena fe consagrado en el art. $1258 \mathrm{Cc}$ y en el art. 57 
reses sociales. Todos los socios contribuyen a la obtención del fin, a todos les afectan los resultados y además puede exigirse que así sea ${ }^{37}$.

Esta decisión determina que se esté ante una sociedad y no ante una comunidad ${ }^{38}$, lo que requiere no solo la existencia de indicios de la voluntad de los contratantes sino la voluntad clara y manifiesta de someterse a un régimen jurídico determinado.

Sin embargo, este criterio no es definitivo. La imposibilidad de desvelar cuál es la voluntad de las partes, la intención real de los contratantes cuando manifiestan su consentimiento, es un problema de (difícil) prueba de lo verdaderamente querido por los intervinientes. Máxime teniendo en cuenta que la mayoría de las veces la opción por la comunidad en lugar de la sociedad se debe más a razones de operativa (su constitución formal y su gestión son más sencillas y baratas) que a razones de fondo.

Además ha de tenerse en cuenta hasta qué punto es admisible que esta decisión de los partícipes sea suficiente para calificar el negocio como sociedad o comunidad sin atender a la verdadera naturaleza de la relación que subyace ${ }^{39}$. Hasta qué punto se trata de una opción basada en el art. 1255 Cc o se está ante un fraude de ley ${ }^{40}$.

\section{D) Atribución legal de personalidad jurídica. La sociedad interna}

La personalidad jurídica se define por la doctrina moderna como un mecanismo de imputación al grupo formado por una pluralidad de personas de todas las relaciones jurídicas activas y pasivas que le afectan. El grupo puede actuar unificadamente frente a terceros y ser

${ }^{37}$ FERNÁNDEZ-ALBOR BALTAR, A., en ARROYO, I. y EMBID, J. M. (Coords.) en Comentarios a la Ley de Sociedades Anónimas, vol. I, Madrid, 2001, p. 471.

${ }^{38}$ FERNÁNDEZ DE LA GÁNDARA, L.: Derecho de sociedades, op. cit. p. 37 y ss.

${ }^{39}$ En palabras de MIQUEL GONZÁLEZ, J. M., "Comunidad y sociedad», en el Notario del siglo XXI, enero-febrero 2014: «Los problemas de calificación de comunidad y sociedad no son problemas de licitud, sino de tipicidad. La autonomía privada es reconocida para configurar las relaciones, tanto de una comunidad como de una sociedad, pero el ordenamiento encaja en un tipo o en otro lo querido por las partes».

${ }^{40}$ En este sentido, GIRON defiende que si la actividad económica de la comunidad, por los términos del planteamiento del problema, es una industria o empresa mercantil no se trata sólo de una "comunidad dinámica» sino de actividad de comerciante, propia de las figuras de sociedad colectiva, el intentar conservar la aplicación del concepto de comunidad, lo que se produce es la permisión de la voluntad negocial contra los preceptos de ius cogens implícitos en la aplicación general al tráfico mercantil de la sociedad colectiva (las referentes a la responsabilidad y al rigor en materia de representación). En consecuencia, no puede admitirse, tanto por razones conceptuales como de política jurídica, que las formas de comunidad actúen en el tráfico mercantil. (Derecho de sociedades, op. cit. p. 84). 
sujeto activo de bienes, derechos y obligaciones de manera separada respecto de sus componentes singulares ${ }^{41}$.

El Código civil reconoce la personalidad jurídica de las sociedades (art. $35 \mathrm{Cc}^{42}$ ), determinando un régimen general (art. $38 \mathrm{Cc}$ ) y remitiendo a las disposiciones relativas a cada tipo de sociedad (art. 36 Cc). La situación de comunidad no está comprendida en el ámbito de esta regulación y, por tanto, carece, con carácter general, de capacidad jurídica y de obrar ${ }^{43}$.

Este criterio decisivo en principio, sin embargo no es determinante. Hay sociedades que carecen de personalidad jurídica y por ello no dejan de ser sociedades. Este fenómeno se produce cuando en la sociedad se mantienen los pactos sociales secretos entre los socios y cada uno de ellos contrata en su propio nombre con terceros (art. 1669 Cc).

Son las conocidas como sociedades internas, en las que la relación jurídica existente se estructura como vínculo obligacional entre los socios -a modo de societas romana- pero sin la voluntad de organizarse jurídicamente en su actuación frente a terceros. La sociedad interna sigue siendo, por tanto, una sociedad pero sin operar como un sujeto de derecho independiente en el tráfico económico.

Esta falta de personalidad jurídica plantea la posibilidad de que las comunidades que ejercen una actividad empresarial sean calificadas como sociedades internas y sigan su mismo régimen.

Si se comparan ambas se observa que sus rasgos característicos son semejantes: en ambas varias personas ponen en común dinero, bienes o industria con ánimo de repartir entre sí las ganancias y ambas carecen de personalidad jurídica. Sin embargo hay una nota esencial que las diferencia: la causa de la falta de personalidad jurídica.

En la sociedad interna la falta de personalidad es consecuencia de la decisión de los socios de mantener secretos los pactos entre ellos y de someterse al régimen específico previsto en la norma. Al carecer de personalidad jurídica, la sociedad no posee un patrimonio propio, de

${ }^{41}$ GARDEAZÁBAL DEL RÍO, F. J., «La sociedad en formación y la sociedad irregular», en Instituciones de Derecho Privado, coord. por J. F. DELGADO DE MIGUEL, tomo VI, vol. 2. ${ }^{\circ}$ Civitas, Madrid, 2004, p. 175.

${ }^{42}$ Sobre el fundamento constitucional de la personalidad jurídica de las sociedades, GARDEAZÁBAL DEL RÍO, F. J., «La sociedad en formación y la sociedad irregular», op. cit., p. 176.

${ }^{43}$ v. epígrafe II. 
ahí que los elementos patrimoniales sean titularidad de los socios y por ello queden sometidos a las normas de la comunidad.

Ahora bien, tal como establece el artículo 392.2 al que remite el artículo 1669 Cc, si existe un contrato entre los miembros, las relaciones entre ellos se regularán por las normas de dicho contrato. La doctrina considera que más que distinguir hay que separar lo que pertenece a cada institución en el plano de la titularidad y en el plano obligatorio. Las reglas de la comunidad de bienes se aplicarán en todo lo relativo a los aspectos jurídico-reales que se puedan plantear pero no a los obligacionales que se regirán por las normas del contrato de sociedad ${ }^{44}$.

Recientemente, la STS, 1. ${ }^{a}$, de 19 de febrero de 2016, en esta línea, ha fijado el régimen de las sociedades internas, diferenciando entre las prescripciones del Código civil que regulan la comunidad de bienes las que estructuran la titularidad sobre el patrimonio o fondo común, que son directamente aplicables a las sociedades internas, y aquellas otras que rigen las relaciones entre los socios que se aplicarán en defecto de contrato de sociedad.

Por el contrario, la causa de la falta de personalidad jurídica de las comunidades que ejercen una actividad se deriva del propio ordenamiento jurídico (imposibilidad de inscripción registral por no estar tipificada como ente jurídico inscribible), pero no de la voluntad de los partícipes. Es más, aunque no están sujetas a publicidad registral son objeto de publicidad desde su nacimiento. Se inscriben en distintos registros administrativos, actúan bajo una razón social -aunque actúen en su propio nombre-, lo que se manifiesta en documentación, anuncios, etc.

Este carácter definitorio de la comunidad es el que hace que no se pueda considerar una sociedad interna -lo que no quiere decir que no sea una relación societaria la existente-, pues, aunque ambas carecen de personalidad jurídica, la sociedad interna aunque sea conocida de hecho, excluye por voluntad propia cualquier actuación unificada frente a terceros bajo una razón social única ${ }^{45}$, mientras que la comunidad se exterioriza en el ejercicio de su actividad precisamente actuando bajo una denominación única.

${ }^{44}$ PAZ ARES, C., «La sociedad en general. Caracterización del contrato», en URÍA, R. y MENÉNDEZ, A., Curso de Derecho Mercantil, vol I, Civitas, Madrid, 1999, p. 452 ss.; y "Las sociedades mercantiles», en Lecciones de Derecho Mercantil, vol. I, dir. por A. MENÉNDEZ y A. ROJO, Civitas, Cizur-Menor, 2016, pp. 364-365.

${ }^{45}$ GARDEAZÁBAL DEL RÍO, F. J., «La sociedad en formación y la sociedad irregular», en Instituciones de Derecho Privado, op. cit., p. 187. 


\section{E) Integración de los criterios}

A falta de una regulación específica y de un único criterio delimitador claro entre sociedad y comunidad de bienes que ejerce una actividad empresarial, la doctrina y la jurisprudencia han visto necesario recurrir a la integración de todos estos criterios ${ }^{46}$ para determinar cuál es la verdadera naturaleza del negocio cuando la situación jurídica resulta dudosa.

Esta es la línea que propugna la Sentencia del Tribunal Supremo, Sala 1. a , de 17 de julio de 2012, que fija las pautas a seguir en el proceso de interpretación:

a) Valoración del título que originó la situación de indivisión: naturaleza mortis causa o ínter vivos y en este último caso valoración de las conductas de las partes como medio interpretativo y de acuerdo a los usos de los negocios o del tráfico.

b) Examen del tipo o modo de explotación de los bienes puestos en común, de forma que, como criterio de interpretación general, la explotación conjunta con criterios y organización de empresa debería entenderse como una situación de sociedad, mientras que su mera utilización y aprovechamiento consorcial debería entenderse como situación de comunidad.

c) Aplicación de las doctrinas de los actos concluyentes y de los propios actos.

d) Respecto a la incidencia de la voluntad su aplicación como criterio interpretativo, ir más allá de la constatación del mero ánimo o disposición de estar en una situación de sociedad, requiriéndose a los partícipes la realización de actos de configuración potestativa que inequívocamente tiendan a la creación de una situación real y efectiva de sociedad.

Por tanto, son los Tribunales quienes, partiendo del análisis del supuesto de hecho concreto planteado, tienen que determinar cuál es la verdadera naturaleza jurídica de la relación subyacente y fijar el régimen jurídico aplicable.

${ }^{46}$ Integración adelantada por GARRIGUES, en un dictamen elaborado en 1954, en el que partiendo del problema de diferenciación entre comunidad y sociedad - «ha sido uno de los más debatidos por la doctrina, sin que los autores hayan encontrado todavía la nota esencial o característica de una y otra institución que permita definir con absoluta seguridad dónde hay una comunidad y dónde existe una sociedad»-, asevera que «poniendo en relación una serie de notas o caracteres no esenciales puede llegarse a obtener una certeza respecto de la naturaleza jurídica de cada situación de hecho» (dictamen 120), Dictámenes de Derecho Mercantil, II, op. cit., pp. 411 ss. 
En conclusión, crear una comunidad para la explotación de una actividad empresarial es posible y admisible, aunque de facto se trate de una sociedad.

\section{CALIFICACIÓN DE LA RELACIÓN JURÍDICA SUBYACENTE}

La doctrina, consciente de la existencia de estas comunidades y de la dificultad para encuadrarlas como comunidades de bienes (de acuerdo con el régimen previsto en el Código civil), admite de forma unánime que son equiparables a una relación societaria. Así se las ha denominado "comunidades mercantiles " $^{47}$, "comunidades societarias $»^{48}$, «comunidades de bienes empresariales» ${ }^{49}$.

Esta equiparación doctrinal se basa en la elaboración de un concepto amplio de sociedad que permite extender su aplicación a esas situaciones. Si se hace abstracción ${ }^{50}$ de requisitos específicos, el contrato de sociedad se podría definir como la unión voluntaria de varios sujetos para la realización de una actividad común con el fin de obtener una ganancia ${ }^{51}$, y las comunidades que ejercen una actividad empresarial cumplen esos requisitos mínimos.

En consecuencia, deben ser calificadas como sociedades, aunque los partícipes manifiesten su voluntad de crear una comunidad y así la denominen en el tráfico. Ahora bien, esta calificación debe ser matizada atendiendo a la naturaleza de la actividad que se desarrolla, según los criterios fijados por nuestro ordenamiento jurídico.

El Código de Comercio establece que serán sociedades mercantiles aquellas que tienen como objeto una actividad comercial o industrial $^{52}$ y que además se constituyen con arreglo a uno de los tipos o formas previstos legalmente.

${ }^{47}$ GARRIGUES, J., Dictámenes de Derecho Mercantil, II, Madrid, 1976.

${ }^{48}$ FERNÁNDEZ DE LA GÁNDARA, L., Derecho de Sociedades, vol. I, op. cit., p. 50.

${ }^{49}$ PAZ-ARES, C., Las sociedades mercantiles, en MENÉNDEZ A. y ROJO, A. (dirs), Lecciones de Derecho Mercantil, vol. I, Civitas, Cizur-Menor, 2016, p. 359.

${ }^{50}$ Abstracción que puede fundamentarse en el art. 22 CE, MIQUEL GONZÁLEZ, J. M. ${ }^{\text {a: }: ~ C o m u n i d a d ~ y ~ s o c i e d a d », ~ e n ~ E l ~ N o t a r i o ~ d e l ~ s i g l o ~ X X I, ~ e n e r o-f e b r e r o, ~ 2014 . ~ S o-~}$ bre los fenómenos asociativos atípicos y las sociedades en sentido estricto o sociedades contractuales, PANTALEÓN, F.: "Asociación y sociedad», en Anuario de Derecho Civil, marzo 1993, en especial, pp. 46-47, 55-56 y notas 6 y 34 .

${ }^{51}$ GARDEAZÁBAL DEL RÍO, F. J., "La sociedad en formación y la sociedad irregular», en Instituciones de Derecho Privado, op. cit., p. 178 ss.

52 Para un estudio de la calificación como mercantil de la actividad, PÉREZ DE MADRID CARRERAS, V., «La mercantilidad de la sociedad en la doctrina de la Direc- 
El Código civil, sin embargo, en su art. 1670, permite que las sociedades civiles atendiendo al objeto a que se consagren revistan las formas reconocidas en el Código de $\mathrm{Comercio}^{53}$. Las sociedades que tengan por objeto social, por ejemplo, el ejercicio de una profesión serán civiles sin perjuicio de que se rijan por el Código de comercio en lo que no se oponga al Código civil.

La actividad empresarial que ejercen estas comunidades debe encuadrarse, pues, entre las operaciones o actividades constitutivas de empresa (art. 1.1 C de c), por lo que deben calificarse como sociedades de naturaleza mercantil, aunque no están constituidas de acuerdo a una forma tipificada ${ }^{54}$.

\section{RÉGIMEN JURÍDICO APLICABLE}

Aceptado por los diferentes operadores jurídicos que la comunidad que ejerce una actividad empresarial se basa en una relación jurídica equiparable a la de la sociedad mercantil, hay que fijar cuál es el régimen jurídico aplicable.

El Código de comercio exige dos requisitos para constituir una sociedad mercantil: la escritura pública y la inscripción en el Registro Mercantil (art. 119). La comunidad que ejerce una actividad empresarial, con carácter general, se constituye en documento privado o público (ante Notario), si bien no puede acceder al Registro Mercantil al no ser sujetos sometidos a inscripción.

Pues bien, las sociedades que no cumplen con estos requisitos y, en concreto, con la inscripción registral se denominan sociedades irregulares. Así, son definidas como sociedades con objeto mercantil que actúa frente a terceros ${ }^{55}$ sin intención de inscribirse. Sociedades en las que existe un contrato social entre varias personas no inscrito y que no va a ser sometida a inscripción registral ${ }^{56}$.

ción General de los Registros y del Notariado. A propósito de la Resolución de 20 de abril de 2010», en Revista Derecho de Sociedades, núm. 36, 2011-1, p. 448.

${ }^{53}$ Un estudio de la naturaleza objetiva y subjetiva de la sociedad en distintos momentos legislativos, en la STS, $1 .^{\mathrm{a}}$, núm. 121/2012, de 7 de marzo.

${ }^{54}$ Sobre atipicidad societaria, FERNÁNDEZ DE LA GÁNDARA, L., Derecho de sociedades, vol. I, op. cit., pp. 42 ss.

${ }^{55} \mathrm{La}$ sociedad debe actuar frente a terceros como una mediante signos externos o hechos concluyentes (publicidad de hecho), pues en caso contrario no se estaría ante un supuesto de irregularidad sino de sociedad interna (v. epígrafe III, D).

${ }^{56}$ VALPUESTA GASTAMINZA, E. M. ${ }^{\mathrm{a}}$ : La sociedad Irregular, RdS monografías, Aranzadi, Pamplona, 1995. 
La no inscripción no va a afectar a la validez de las sociedades si bien no se puede admitir que se rijan por el régimen previsto para un tipo específico de sociedad mercantil ${ }^{57}$. Las consecuencias de la falta de inscripción, no afectan a la personalidad jurídica ${ }^{58}$, sino que se limitan al ámbito de la publicidad y de la responsabilidad. La no oposición frente a terceros de buena fe de los pactos sociales contrarios a las normas legales de derecho positivo y la no posibilidad de limitar la responsabilidad al no tener constancia de la garantía que la sociedad ofrece (el capital aportado) son los dos efectos inmediatos de la irregularidad.

La doctrina y la jurisprudencia admiten de manera unánime que el régimen aplicable a estas sociedades no inscritas (irregulares) es el de la sociedad colectiva ${ }^{59}$, por ser la sociedad general del tráfico mercantil ${ }^{60}$ cuando se da el presupuesto objetivo de ejercicio del comercio $^{61}$ y por contener la regulación más protectora de los intereses de los terceros con los que se relaciona (art. $127 \mathrm{C}$ de c). Además se fija una garantía adicional la responsabilidad solidaria de los encargados de la gestión social por las operaciones que en nombre de la sociedad hayan contratado con terceros (art. $120 \mathrm{Cc}$ ), como medida de protección de los terceros.

${ }^{57}$ La sociedad no inscrita no deja de tener personalidad jurídica, lo que la publicidad registral le confiere es la personalidad jurídica del tipo concreto elegido en su constitución (art. 33 LSC).

${ }^{58}$ v. STS, $1 .^{\mathrm{a}}$, núm. 740/2010 y las resoluciones citadas.

${ }^{59}$ PAZ ARES, Curso de Derecho Mercantil, I, op. cit., p. 508, se basa en lo que denomina principio de imposición de formas, para determinar la adscripción forzosa de las realidades asociativas que no quedan cubiertas por un tipo especial al tipo general, la «reconducción forzosa de las sociedades efectivamente practicadas al tipo general de la sociedad colectiva». También se trata la "conversión" a sociedad colectiva, en VALPUESTA GASTAMINZA, E. M. ${ }^{\mathrm{a}}$ : La sociedad irregular, op. cit.

${ }^{60}$ PAZ ARES, define a la sociedad colectiva como sociedad general del tráfico mercantil, de manera que sus normas se aplican no sólo a las sociedades expresamente constituidas como colectivas, sino también a las sociedades contraídas tácitamente sin nomen iuris (por ejemplo, a una comunidad hereditaria que prosigue indefinidamente la explotación de la empresa del difunto) y a aquellas otras sociedades que, no obstante haberse constituido con un determinado nomen iuris, no pueden subsistir bajo la forma elegida (como las comunidades de bienes y las sociedades civiles constituidas para la explotación de una actividad mercantil), en «Sociedad colectiva: introducción y administración», en URÍA, R. y MENÉNDEZ, A., Curso de Derecho Mercantil, I, op. cit., p. 574.

${ }^{61}$ La doctrina matiza la normativa a aplicar según el objeto: objeto empresarial régimen de la sociedad colectiva, objeto no empresarial régimen de la sociedad civil. PAZ-ARES, C., Las sociedades mercantiles, en MENÉNDEZ, ROJO, A. (dirs), Lecciones de Derecho Mercantil, vol. I, op. cit., p. 361; también MIQUEL GONZALEZ, J. M., voz Comunidad de Bienes, en Enciclopedia Jurídica Básica, vol. I, Madrid, 1995, p. 1316. 
Lo mismo sucede con las sociedades civiles con objeto mercantil a las que podrían asimilarse las comunidades que ejercen una actividad empresarial. Este tipo social no está reconocido en el Derecho de sociedades, como se desprende del artículo $122 \mathrm{C}$ de c que reserva el ejercicio de la actividad mercantil a los tipos mercantiles reconocidos expresamente por el Código. Pero son una realidad en la práctica jurídica y económica ${ }^{62}$.

La doctrina se ha pronunciado sobre la naturaleza de estas sociedades civiles con objeto mercantil y considera que si la sociedad es constituida como civil pero con objeto mercantil no es sociedad civil sino sociedad mercantil colectiva ${ }^{63}$, aunque la voluntad de los socios haya sido constituirla como civil, ya que las normas reguladoras de la sociedad mercantil tienen carácter imperativo al estar establecidas en interés del tráfico mercantil. La jurisprudencia, en el mismo sentido, considera que las sociedades civiles con objeto mercantil son sociedades de naturaleza mercantil, dado su fin, pero sin acceso al Registro Mercantil $^{64}$, lo que las convierte en un tipo de sociedad irregular ${ }^{65}$.

La regulación del proyectado Código Mercantil cierra el debate sobre estas sociedades, al fijar un criterio doble de mercantilidad por el objeto y la forma. Así que todas las sociedades que tengan por objeto la producción o el cambio de bienes o la prestación de servicios para el mercado serán mercantiles con independencia de la forma adoptada (art. 211-1).

Pues bien, al margen de la atribución de personalidad jurídica por la inscripción, si se comparan los caracteres de las comunidades que ejercen una actividad empresarial con los de la sociedad irregular, se puede observar que comparten una misma estructura: a) desarrollo de una actividad mercantil; b) fundamento en un contrato regulador y organizador de la actividad; c) contrato no inscrito; d) actuación en el tráfico económico frente a terceros como un único sujeto; e) responsabilidad por las deudas comunes agravada.

${ }^{62}$ Sociedades, actualmente, objeto de estudio por la Sección Segunda de la Comisión General de Codificación, de lo Mercantil.

${ }^{63}$ VICENT CHULIÁ, F.: Introducción al Derecho Mercantil, vol. I, op. cit., p. 487.

${ }^{64}$ El RD 1867/1998, de 4 de septiembre, modificó el art. 81 e introdujo un nuevo art. 269 bis al Reglamento del Registro Mercantil, para la inscripción de las sociedades civiles, tuvieran o no forma mercantil. Dicho artículo fue declarado nulo por STS, Sala 3. ${ }^{\text {a }}$, de 24 de febrero de 2000, por carecer de norma legal habilitante. V. MASIDE MIRANDA, E.: «Las sociedades civiles y el Registro Mercantil», en Anuario da Facultade de Dereito da Universidade da Coruña, núm. 6, 2002, pp. 447-458.

${ }^{65}$ SAP Santa Cruz de Tenerife, Sec. 4. ${ }^{a}$, núm. 158/2013, de 24 de abril, SAP Alicante, Sec. 9. ${ }^{a}$, núm. 735/2012, de 27 de diciembre. 
Así, a título de ejemplo, la Sentencia de la Audiencia Provincial de Castellón de 7 de enero de $2004^{66}$, en el caso de una entidad legalmente establecida con su NIF correspondiente y un establecimiento abierto al público con denominación mercantil de comunidad de bienes, denominación que utiliza frente a terceros, según consta en las facturas libradas por la misma, declara que la verdadera naturaleza del acto por el que se constituye la comunidad de bienes es el de una sociedad irregular.

Se ha llegado incluso a decir que la «comunidad de bienes» como forma de organización de la empresa colectiva, constituye un monstrum jurídico, que hay que desterrar de nuestra praxis negocial, ya que tales organizaciones, de comunidades, sólo tienen el nombre. Son sociedades y, además, porque se han constituido con el propósito de actuar unificadamente en el tráfico, son sociedades externas y, por tanto, personificadas, aunque sean irregulares por no haberse inscrito en el Registro Mercantil ${ }^{67}$.

La vía de la irregularidad ha sido considerada también como el medio que ha permitido declarar el concurso de las comunidades por su asimilación a la sociedad ${ }^{68}$. No hay que olvidar, en estos casos, que la comunidad de bienes, aunque tenga un objeto mercantil, no tiene personalidad jurídica y, por tanto, no tiene capacidad como sujeto independiente distinta a la de sus miembros.

En definitiva, y de acuerdo con la doctrina científica, la del Tribunal Supremo y la de la Dirección General de los Registros y del Notariado, las comunidades que ejercen actividades empresariales se consideran sociedades desde el momento que los contratantes se obligaron a poner en común determinados bienes con intención de obtener un lucro. Son mercantiles por su objeto, puesto que desarrollan una actividad constitutiva de empresa bajo una razón unificada en el tráfico. Y la relación societaria es calificable como irregular, por su falta de inscripción.

Esta caracterización determina la aplicación del régimen general de las sociedades mercantiles no tipificadas, es decir, el régimen

${ }^{66}$ Calificación que también le permite declarar su legitimación pasiva -capacidad para ser parte en juicio-, de acuerdo con el art. 6.1.5. ${ }^{\circ}$ LEC (sentencia núm. 343/2004).

${ }^{67}$ PAZ ARES, C.: Curso de Derecho Mercantil, op. cit. p. 453.

${ }^{68}$ PULGAR EZQUERRA, J.: La declaración del concurso de acreedores, Madrid, 2005, p. 290 ss, la irregularidad dota a la comunidad de bienes «de una personalidad jurídica básica o general y les permite ser sujetos pasivos del concurso, con los problemas derivados no obstante de la irregularidad». 
de la sociedad colectiva ${ }^{69}$ (reconocida expresamente en el Anteproyecto de Código Mercantil, en su función supletoria, como tipo subsidiario aplicable a los supuestos de sociedad no inscrita o sociedad irregular).

\section{PROPUESTA LEGISLATIVA DE REGULACIÓN}

La importancia del reconocimiento jurídico y de la regulación de la comunidad que ejerce una actividad empresarial se muestra, aunque limitada a su ámbito específico, en la reciente Ley 27/2014, de 27 de noviembre, del Impuesto sobre Sociedades. Esta Ley sujeta, a diferencia de las leyes anteriores, al impuesto a las sociedades civiles con objeto mercantil (art. 7). Y la Agencia Tributaria en interpretación de esta norma determina que cuando las comunidades de bienes se constituyan para poner en común dinero, bienes o industria con el ánimo de obtener ganancias y lucros comunes se estará en presencia de una sociedad civil con objeto mercantil (instrucciones sobre la constitución de sociedades civiles o comunidades de bienes a partir de 2015, de 13 de noviembre de 2015).

Aunque aclarada posteriormente esta postura por Instrucción de 22 de diciembre, en el sentido de considerar que «las comunidades de bienes que tengan finalidad asociativa para la realización de una actividad económica no estarán sujetas al impuesto» (Instrucción de 22 de diciembre), lo que se deduce de las referidas instrucciones es la intención del legislador: la forma jurídica de comunidad de bienes o sociedad civil con objeto mercantil no depende de la voluntad de los partícipes o socios sino de la calificación de la naturaleza jurídica de la entidad.

El legislador consciente de la importancia jurídica de la comunidad de bienes como instrumento para el ejercicio de una actividad mercantil, en su tarea de adaptar las leyes a la realidad, ha previsto una regulación específica, fijando su naturaleza jurídica, de forma que se diferencie de la institución de la comunidad regulada en el Código civil y se equipare a las sociedades mercantiles.

${ }^{69}$ Algunos autores propugnan la regulación unitaria del contrato de sociedad en un Código de Sociedades, sin distinguir entre civil y mercantil. Se regularía una sociedad general cuya utilidad sería garantizar la aplicación de un régimen jurídico adecuado ante las distintas controversias suscitadas entre los socios y frente a terceros por sociedades irregulares, atípicas, ocultas o internas (PÉREZ DE MADRID CARRERAS, V., «La mercantilidad de la sociedad en la doctrina de la Dirección General de los Registros y del Notariado. A propósito de la Resolución de 20 de abril de 2010», en Revista Derecho de Sociedades, núm. 36, 2011-1, p. 453). 
La propuesta de Código de Sociedades, aprobada el 15 de mayo de $2002^{70}$, en su título IV "De las sociedad mercantiles no inscritas», del Libro I «De las disposiciones generales», ya contenía un artículo dedicado a «Comunidad y sociedad». Este artículo, el número 40, establece que se aplicarán las normas relativas a las sociedades mercantiles no inscritas (sociedades irregulares) «a la comunidad voluntaria que explote un establecimiento dedicado a la producción o al intercambio de bienes o servicios para el mercado», haciendo extensivo el régimen "a la comunidad incidental que tenga igual objeto, transcurrido un año desde que se hubiera constituido» ${ }^{71}$.

Actualmente, el Anteproyecto de ley de Código Mercantil, aprobado en Consejo de Ministros de 30 de mayo de 2014, en una línea continuista con la propuesta de Código de Sociedades, reconoce ya explícitamente esta figura jurídica bajo la denominación de «comunidad de empresa» (proyectado artículo 213-34), encuadrada en las normas del Capítulo III ( De la constitución de las sociedades mercantiles») y, en concreto, de la Sección 7. ${ }^{\mathrm{a}}$ ( De la sociedad mercantil no inscrita»).

Se está reconociendo su naturaleza de sociedades mercantiles pero irregulares (no inscritas) y, en consecuencia, han de someterse al mismo régimen que éstas. Régimen basado en la aplicación preferente de lo pactado en el contrato de sociedad y supletoriamente por las normas de la sociedad colectiva, con responsabilidad agravada de los socios y administradores frente a terceros por las deudas sociales (responsabilidad personal, ilimitada y solidariamente sin necesidad de previa excusión del patrimonio social).

Con esta propuesta se reconocen y legitiman las comunidades que ejercen una actividad empresarial, lo que evitará problemas de calificación e interpretación sobre su naturaleza jurídica y régimen jurídico, pero además se dicta una norma que supone dar seguridad jurídi-

${ }^{70}$ Propuesta elaborada por la Ponencia Especial de la Sección de Derecho Mercantil de la Comisión General de Codificación, compuesta por los Excmos. Sres. Prof. Dr. D. Fernando Sánchez Calero, Prof. Dr. D. Alberto Bercovitz Rodriguez-Cano y Prof. Dr. D. Ángel Rojo Fernández-Rio.

${ }^{71}$ LACRUZ BERDEJO, en el estudio de la comunidad hereditaria, se planteó ya la necesidad de examinar las causas de la demora en su liquidación, para determinar cuál sería el verdadero régimen aplicable. Finalmente, concluye que en el caso de la «continuación de un negocio o empresa del causante por los herederos con o sin convención de indivisión, pero con ánimo de seguir unidos en la explotación», si se trata de empresas mercantiles, correspondería la «aplicación de reglas y principios propios de la sociedad en concepto de sociedad irregular o de hecho (LACRUZ BERDEJO, J. L. y SANCHO REBULLIDA, F., Elementos de Derecho Civil, V, Derecho de Sucesiones, Barcelona, 1981, p. 122). 
ca a su actuación en el tráfico económico, sobre todo, en protección de los terceros.

\section{CONCLUSIONES}

El ejercicio de la actividad empresarial por las comunidades de bienes es una realidad presente en nuestra práctica jurídica y económica, cuya existencia no se puede desconocer. Sus miembros tienen como objeto la explotación de una empresa con el fin de obtener un lucro y para ello, aportando bienes o derechos, actúan de forma organizada, bajo una denominación común, en el tráfico jurídico-económico. Buscan conseguir una apariencia unificada, una subjetivación, en el tráfico aunque carezcan de personalidad jurídica.

Este fenómeno complejo en que confluyen relaciones pertenecientes a distintos ámbitos (vínculos obligacionales internos; titularidades reales; apariencia, publicidad y relaciones jurídicas externas) y los conflictos planteados en torno al mismo, han planteado, desde antiguo, a los intérpretes del Derecho, la necesidad de fijar la verdadera naturaleza jurídica de esta relación compleja, máxime atendiendo a su actuación en el tráfico jurídico-económico.

En esta labor de interpretación, integración y calificación, los Tribunales y la doctrina científica, se han basado no solo en la voluntad manifestada por los partícipes sino en la realidad derivada de sus actos (constitutivos, de organización y de explotación de la actividad).

Así, tras analizar los rasgos esenciales de estas comunidades y las diferencias y similitudes con otras figuras (origen, voluntad de los miembros, fin, actividad, personalidad jurídica...) coinciden en: a) la separación de la comunidad que ejerce una actividad empresarial de la regulación de la comunidad de bienes del Código civil, basada en una concepción estática de mera conservación y disfrute de bienes; y b) la equiparación de esta forma de explotación con la sociedad.

Ahora bien, consideradas como sociedades es necesario determinar el tipo de sociedad y la situación societaria en que encuadrarlas. Así, las comunidades al ejercer una actividad empresarial deben calificarse, por razón de su objeto (explotación de una empresa), como sociedades mercantiles. Además, sociedades que no cumplen los requisitos de forma, principalmente la inscripción registral, exigidos 
para las sociedades mercantiles, lo que supone que se encuentran en situación de irregularidad.

En consecuencia, se califican como sociedades mercantiles irregulares, por lo que el régimen jurídico aplicable debe ser el previsto para las situaciones de irregularidad societaria: el régimen de la sociedad colectiva, considerada la sociedad general del tráfico mercantil, con la responsabilidad agravada de los gestores (art. $120 \mathrm{C} \mathrm{de} \mathrm{c.).}$

Las últimas propuestas legislativas en materia de Derecho de sociedades vienen contemplando ya específicamente estos supuestos de comunidad como sociedades mercantiles no inscritas (sociedades irregulares).

En concreto, el Anteproyecto de Código Mercantil viene a dar ya reconocimiento legal al ejercicio de actividad empresarial por las comunidades de bienes, con la aplicación del tratamiento de la sociedad no inscrita (sociedad irregular) a las figuras de comunidad voluntaria e incidental de empresa, que delimita como «comunidad voluntaria que explote una empresa o cualquier otra unidad productiva de bienes o servicios» $\mathrm{y}$ "comunidad incidental que tenga igual objeto, siempre que en este caso haya transcurrido un año desde su nacimiento».

Su aprobación, además de legitimar y regular este instrumento técnico, dará apoyo legal general a aquellas normas sectoriales que vienen equiparando, a sus propios fines, ambas realidades jurídicas (comunidad que ejerce una actividad empresarial y sociedad).

\section{BIBLIOGRAFÍA}

AA. VV., Bienes en común, dir. por S. Nasarre Aznar, Tirant lo Blanch, Valencia, 2015.

AA. VV., Comunidad de bienes, coord. por M. J. Reyes López, Tirant lo Blanch, Valencia 2014.

ALBALADEJO, M., "La distinción entre comunidad y sociedad», en Actualidad Civil, núm. 33, 1995-3, págs. 669 a 682.

- Derecho Civil, III Derecho de Bienes, Edisofer, Barcelona, 2002.

ALBIEZ DOHRMANN, K. J., "Contratos sobre comunidades convencionales. Cláusulas usuales», en Comunidad de bienes, coord. por M. ${ }^{\mathrm{a}}$ J. Reyes López, Tirant lo Blanch, Valencia, 2014, págs. 1023-1075. 
BAYONA GIMÉNEZ, J. J., Tributación de la comunidad de bienes, Marcial Pons, Madrid, 1997.

BELTRÁN DE HEREDIA Y CASTAÑO, J., La comunidad de bienes en Derecho Español, Editorial Revista de Derecho Privado, Madrid, 1954.

CÁMARA, M. de la, Estudios de Derecho Mercantil, I, Editoriales de Derecho Reunidas, Madrid, 1977.

CANO ZAMORANO, L., «La comunidad de bienes y su relación con el Registro Mercantil», en M. J. Reyes López (Coord.), Comunidad de bienes, Tirant lo Blanch, Valencia, 2014, págs. 703-727.

FERNÁNDEZ-ALBOR BALTAR, A., Comentarios a la Ley de Sociedades Anónimas, vol. I, coord. por I. Arroyo, y J. M. Embid, Madrid, 2001.

FERNÁNDEZ DE LA GÁNDARA, L., Derecho de Sociedades, vol. I, Tirant lo Blanch, Valencia, 2010.

GARDEÁZABAL DEL RÍO, F. J., «La sociedad en formación y la sociedad irregular», en Instituciones de Derecho Privado, coord. por DELGADO DE MIGUEL, J. F., tomo VI, vol. 2. ${ }^{\circ}$ Civitas, Madrid, 2004, págs. 171-322.

GARRIGUES, J., Dictámenes de Derecho Mercantil, II, Madrid, 1976.

GIRON TENA, J., Derecho de Sociedades, tomo I, Madrid 1976.

GRIMALDOS GARCÍA, M. ${ }^{\mathrm{a}}$ I., “¿Sociedad Interna o comunidad de bienes?: de los criterios de distinción en nuestra jurisprudencia. A propósito de la STS de 17 de julio de 2012», en Diario La Ley, núm. 8056.

LACRUZ BERDEJO, J. L. y SANCHO REBULLIDA, F., Elementos de Derecho Civil, V, Derecho de Sucesiones, Barcelona, 1981.

MASIDE MIRANDA, E., «Las sociedades civiles y el Registro Mercantil», en Anuario da Facultade de Dereito da Universidade da Coruña, núm. 6, 2002, págs. 447-458.

MENÉNDEZ, A. y ROJO, A. (dir.), Lecciones de Derecho Mercantil, vol. I, Civitas, Cizur-Menor, 2016.

MIQUEL GONZÁLEZ, J. M., Voz «Comunidad de Bienes», en Enciclopedia Jurídica Básica, vol. I, Madrid, 1995, págs. 1314-1321.

— «Comentario al art. 392 Cc», en Código Civil y Compilaciones Forales, dir. por M. Albaladejo, Madrid, 1985 (vlex.com/vid/articulo-392-229937) 
— «Comunidad y sociedad», en El Notario del Siglo XXI, enero-febrero, 2014, pág. 115 ss.

PANTALEÓN, F., «Asociación y sociedad (A propósito de una errata del Código Civil)», Anuario de Derecho Civil, enero-marzo, 1993, págs. 5-56.

PAU PEDRÓN, A., "Comunidad funcional», en Libro Homenaje a Manuel Peña Bernaldo de Quirós y Antonio Ipiéns Llorca, Colegio de Registradores de la Propiedad y Mercantiles de España, Madrid, 1996, pág. 281 ss.

PAZ-ARES, C., Curso de Derecho Mercantil, dir. por URÍA, R. y MENÉNDEZ, A., I, Civitas, Madrid, 1999.

PÉREZ DE MADRID CARRERAS, V., «La mercantilidad de la sociedad en la doctrina de la Dirección General de los Registros y del Notariado. A propósito de la Resolución de 20 de abril de 2010», en Revista Derecho de Sociedades, núm. 36, 2011-1, págs. 447-453.

PÉREZ PÉREZ, E., Propiedad, Comunidad y Finca Registral, Colegio de Registradores de la Propiedad y Mercantiles de España, Madrid, 1995.

QUESADA SÁNCHEZ, A. J., Las sociedades civiles sin personalidad jurídica en el ordenamiento jurídico español, Universidad de Málaga, 2003.

REDONDO TRIGO, F., «De nuevo sobre la personalidad jurídica de la sociedad civil en la Resolución de la Dirección General de los Registros y del Notariado, de 25 de junio de 2012», en Revista Crítica de Derecho Inmobiliario, núm. 726, págs. 1258-1291.

SANTOS BRIZ, J., Derecho civil, teoría y práctica. Tomo II. Derecho de cosas, Editorial Revista de Derecho Privado, Madrid, 1973.

TENA PIAZUELO, I., La caracterización de la sociedad civil y su diferencia con la comunidad de bienes, Tirant lo Blanch, Valencia, 1994.

URÍA, R. y MENÉNDEZ, A. (dir.), Curso de Derecho Mercantil, vol I, Civitas, Madrid, 1999.

VALPUESTA GASTAMINZA, E. M. ${ }^{\text {, }}$, La sociedad Irregular, RdS monografías, Aranzadi, Pamplona, 1995.

VICENT CHULIÁ, F., Introducción al Derecho Mercantil, vol. I, Tirant lo Blanch, Valencia, 2012. 
